GSA Data Repository 2017072

Temperature and volume of global marine sediments

LaRowe et al.

\title{
1 SUPPLEMENTARY SECTION
}

As indicated in the its caption, Figure S1 shows the three domains considered in this

3 study. These domains were created in order to specify values of parameters $\left(\phi_{0}, c_{0}, \lambda_{s}\right)$ required

4 to calculate the volume of pore water and the temperature of sediments on a global scale. These

5 parameter symbols refer to the porosity of sediments at the sediment-water interface porosity

$6\left(\phi_{0}\right)$, the sediment compaction length scale $\left(c_{0}\right)$ and the thermal conductivity of the solid phases

7 in sediments $\left(\lambda_{s}\right)$. See Table 1 for their values and the main text for the equations that they are

8 used in.

9 Figure S2 summarizes the methods section in the main text in a single image in order to

10 communicate the series of actions that were taken to carry out the calculations that form the

11 results of our manuscript.

12 The panels shown in Figure S3 essentially combine the two key results in this

13 manuscript: the global distribution of temperature in marine sediments and the volume of pore

14 water in marine sediments. The combined result depicts the volume of pore water in the same

15 temperature intervals shown in Figure 1 and Table 2. Unlike the sediment thickness shown in

16 Figure 1 and corresponding volumes listed in Table 2, the volumes of pore water are not greatest

17 at the higher temperatures. This is because although there is a greater thickness of sediments at

18 the higher temperatures, the porosity and thus the volume of pore fluids decreases exponentially

19 with depth according to the porosity model that we have adopted (Eq. 1).

\section{SUPPLEMENTARY FIGURE CAPTIONS}

22 Figure S1. Illustration of the shelf, margin and abyss domains considered in this study. The

23 location of the continental margin boundaries was adopted from Vion and Menot (2009): shelf 
24 environments (dark gray) roughly correspond to water depths $<200 \mathrm{~m}$, with the exception of the

25 Antarctic region where shelf area corresponds to water depths $<500 \mathrm{~m}$; areas deeper than $\sim 3500$

$26 \mathrm{~m}$ are taken to be abyssal plain (white). The remaining light gray regions correspond to the

27 continental margin.

29 Figure S2. Overview of the workflow used to describe the model, characterize the domains and

30 carry out the calculations required to generate the maps shown in Figures $1 \&$ S3 and the data

31 displayed in Table 2.

32

33 Figure S3. Volume of pore water in global marine sediments in discrete temperature intervals. In

34 each panel, the volume of marine sediment pore water within the indicated temperature range is 35 given for a particular grid cell. Note that the scale, and therefore the color palette, for each panel 36 is different, especially that for the coldest $\left(<0{ }^{\circ} \mathrm{C}\right)$ pore fluids and those ranging from $0-60{ }^{\circ} \mathrm{C}$. 


\section{) UJ XIH6ロ}

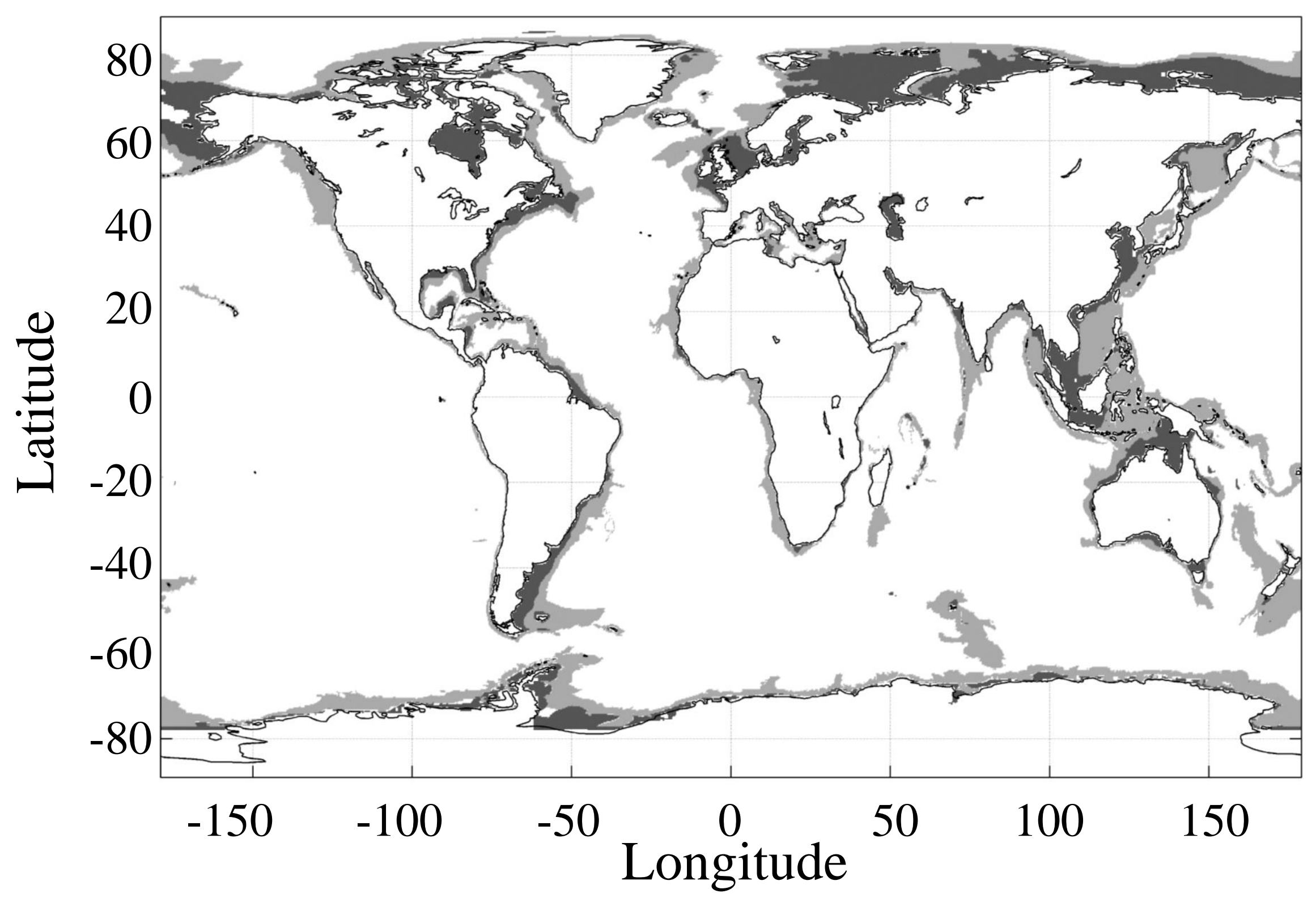




\section{Figure S2. Workflow}

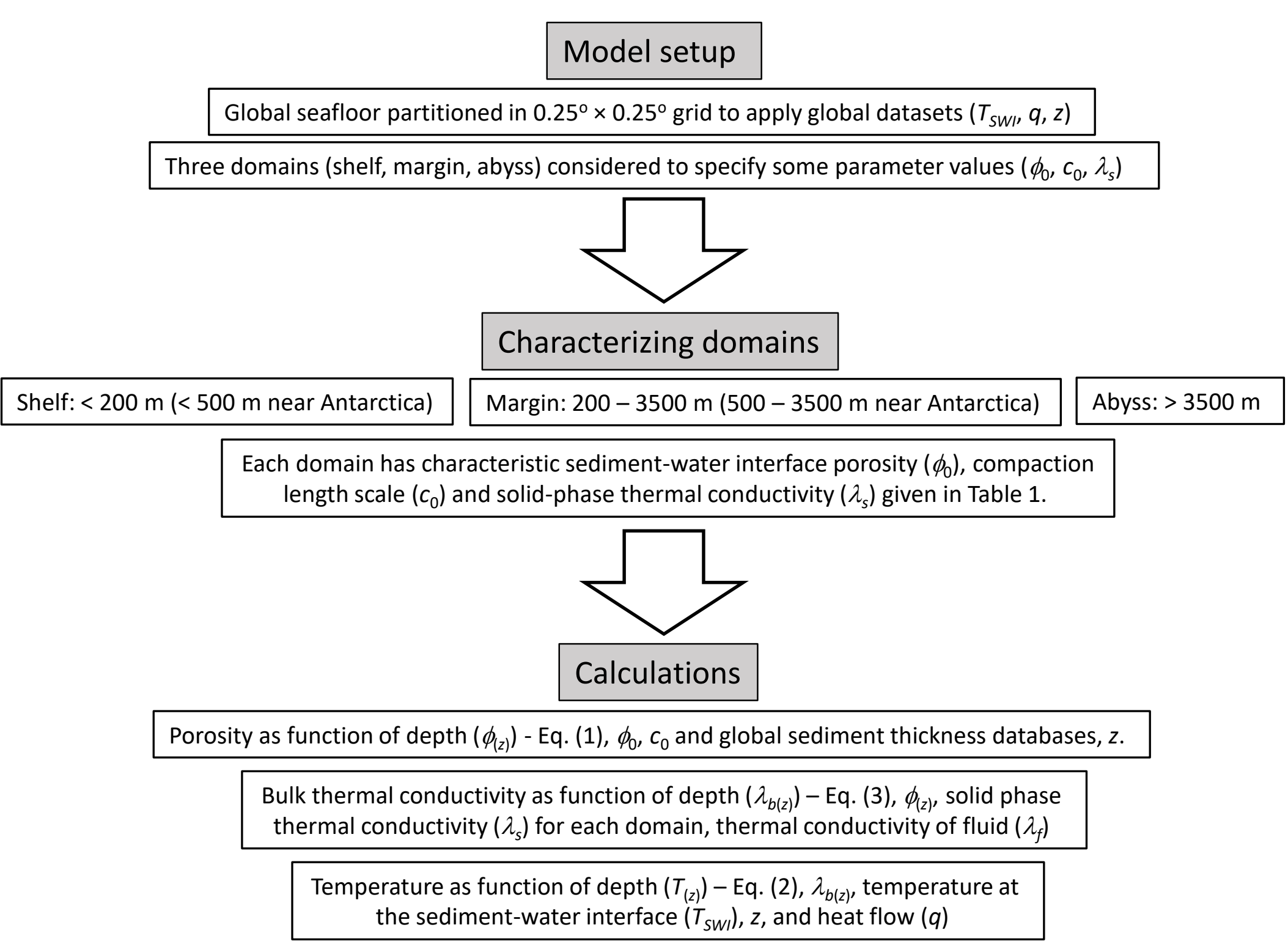




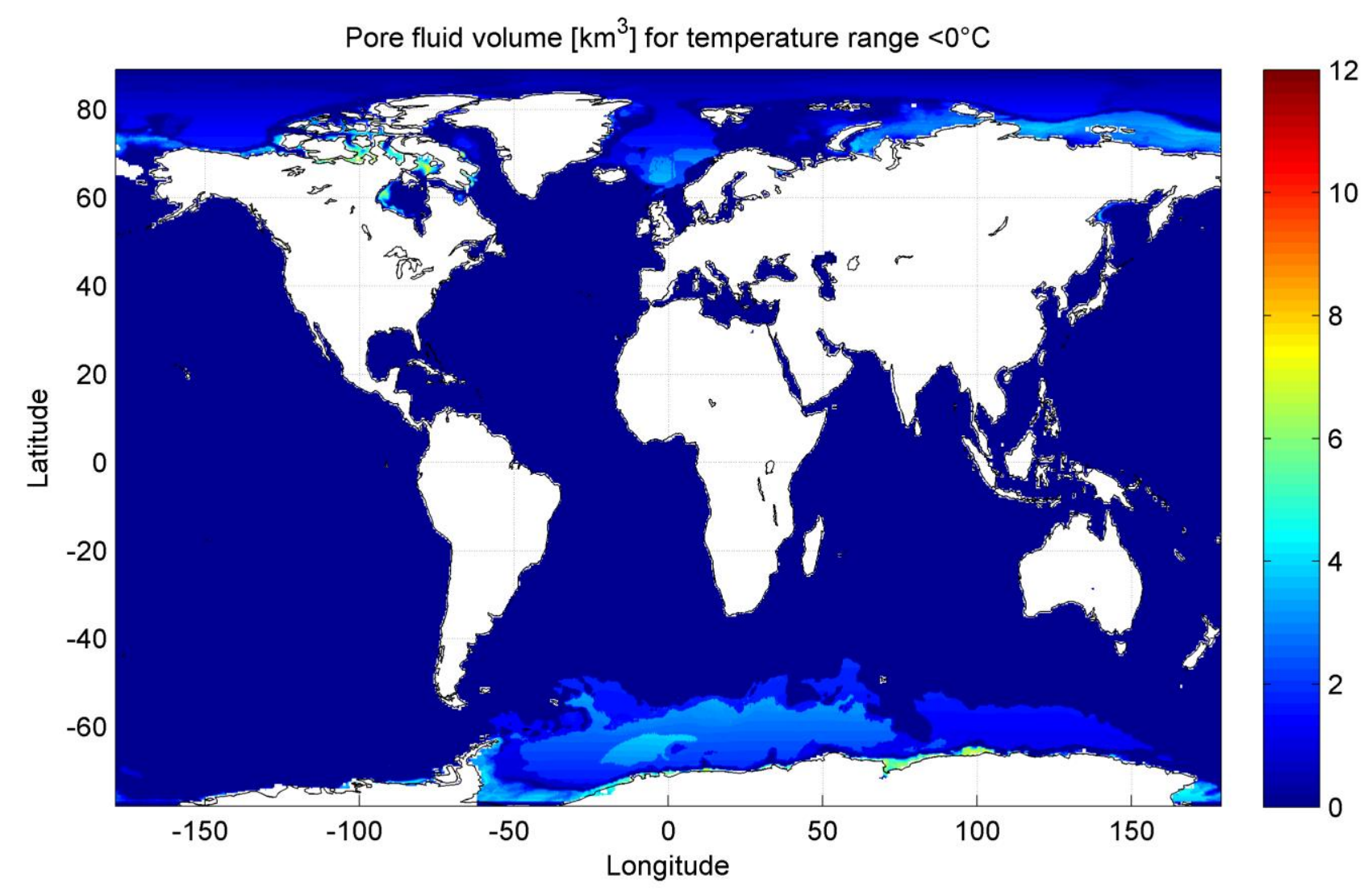




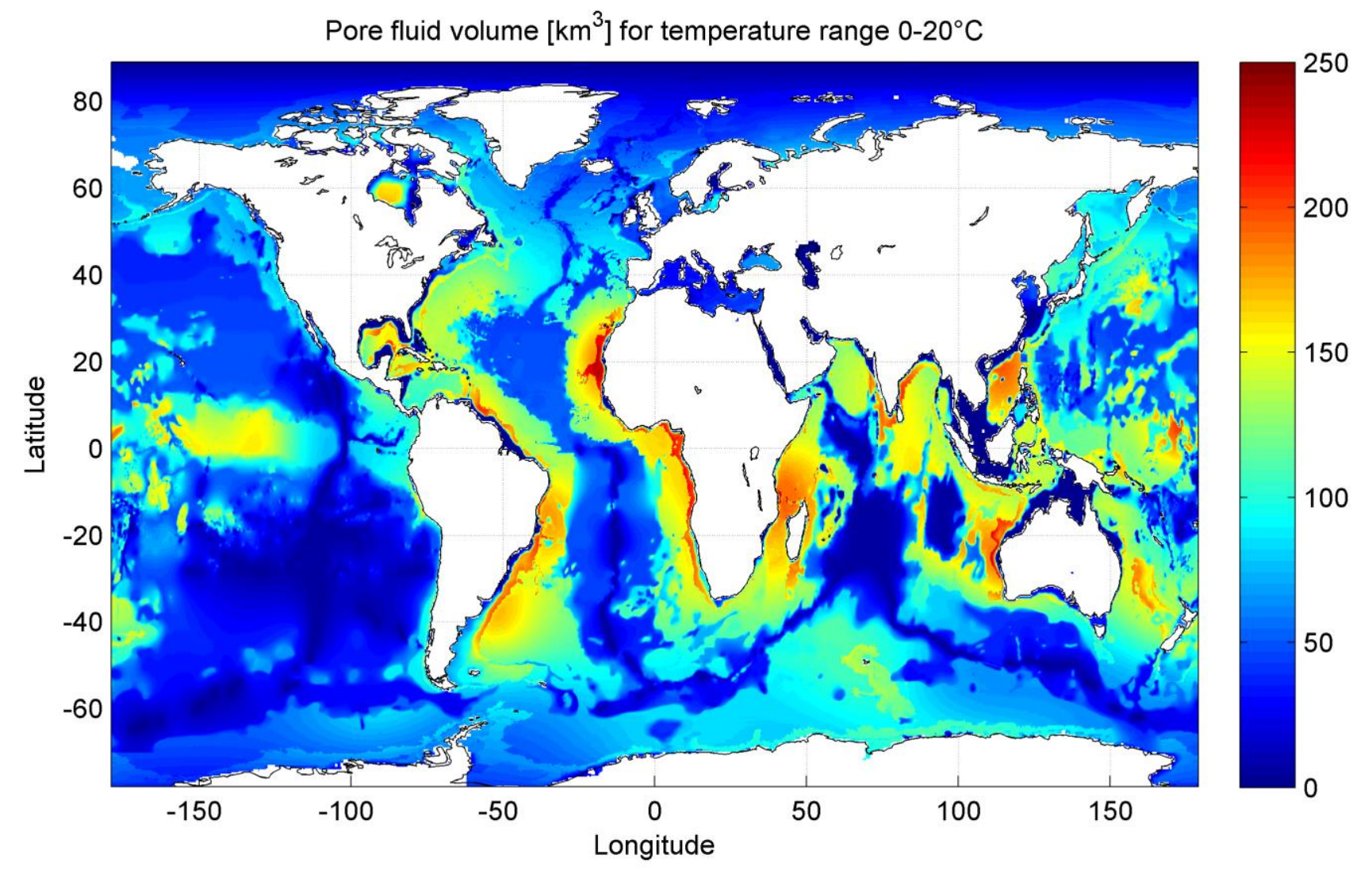




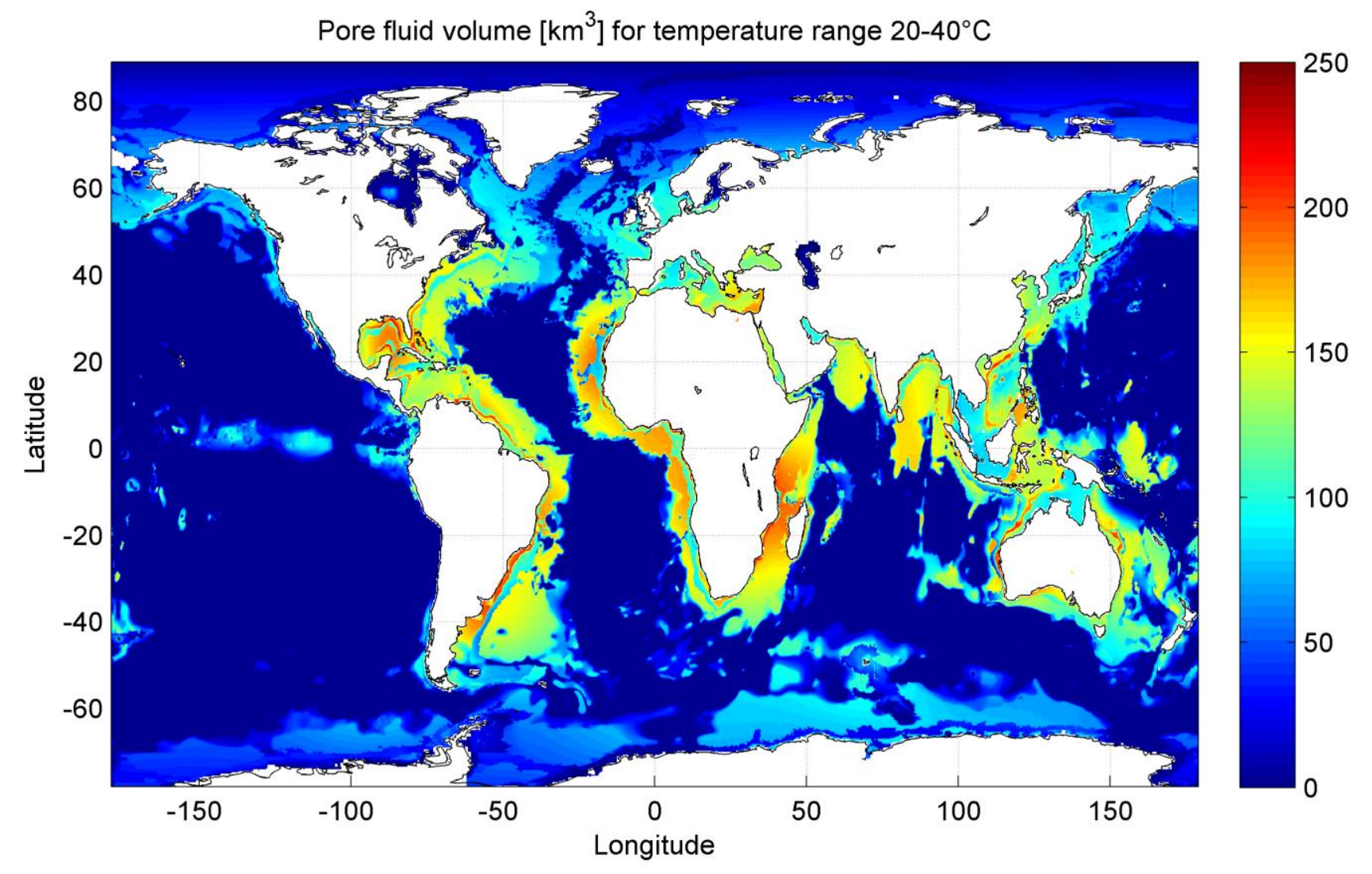




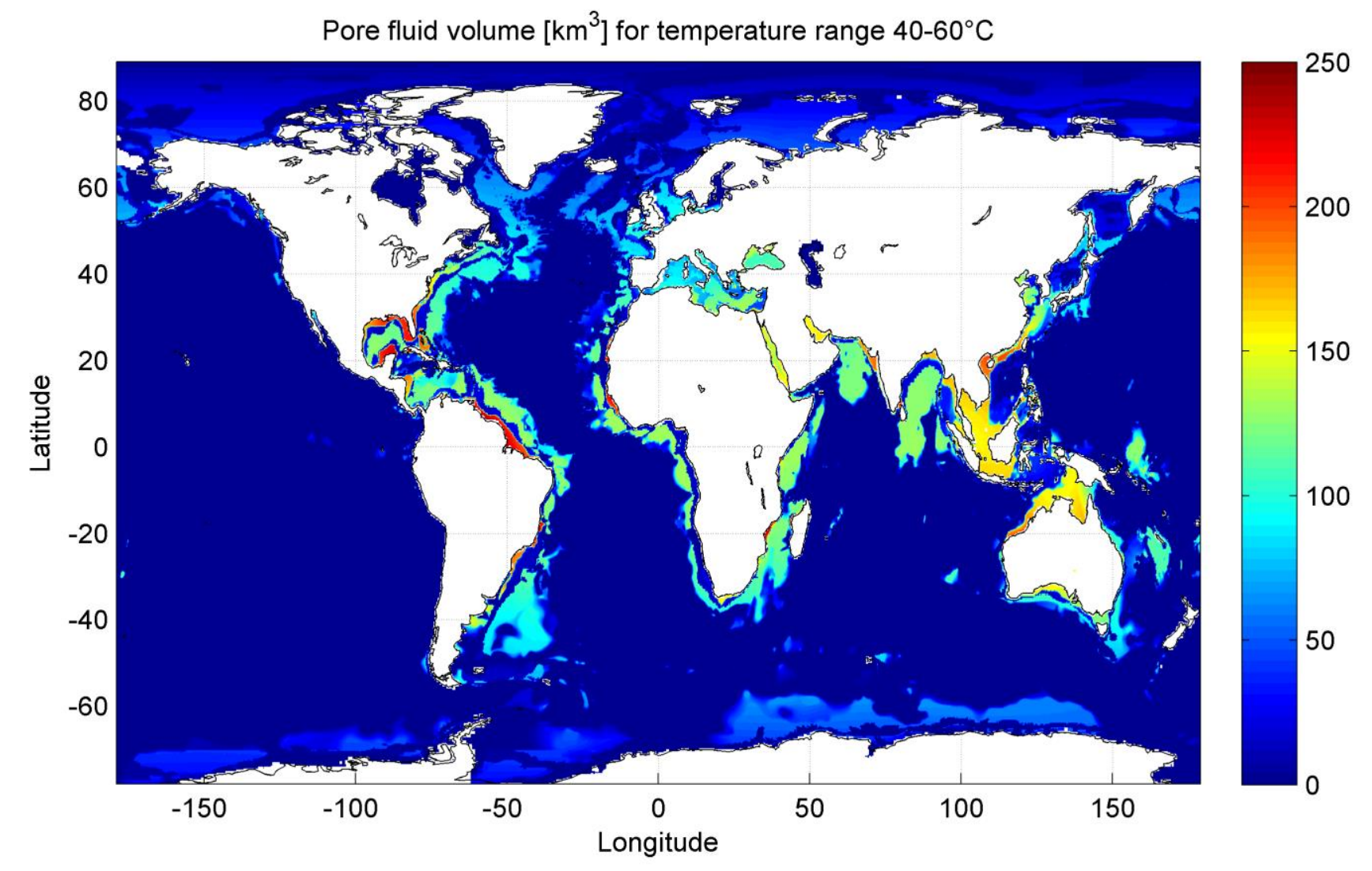




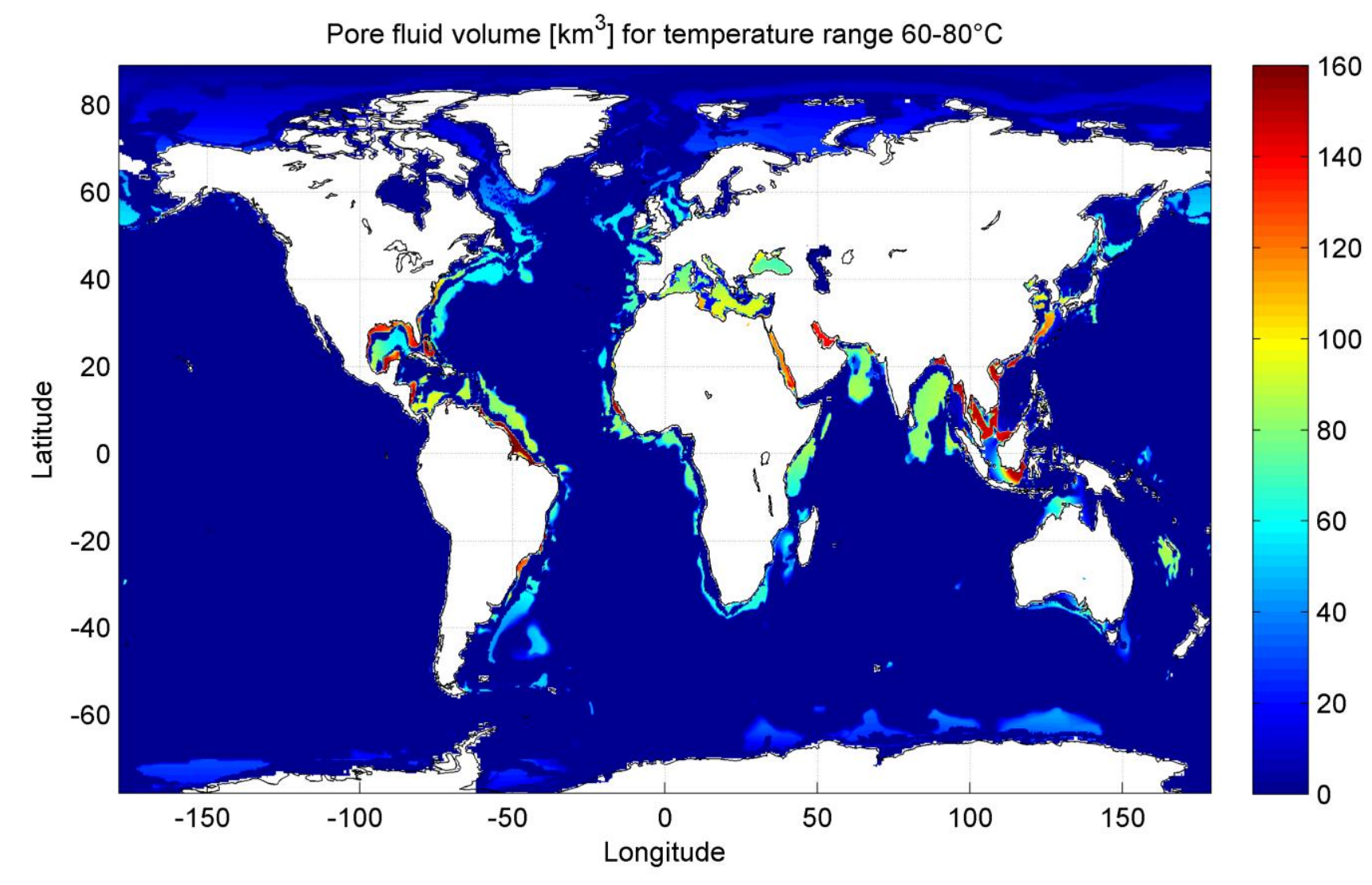




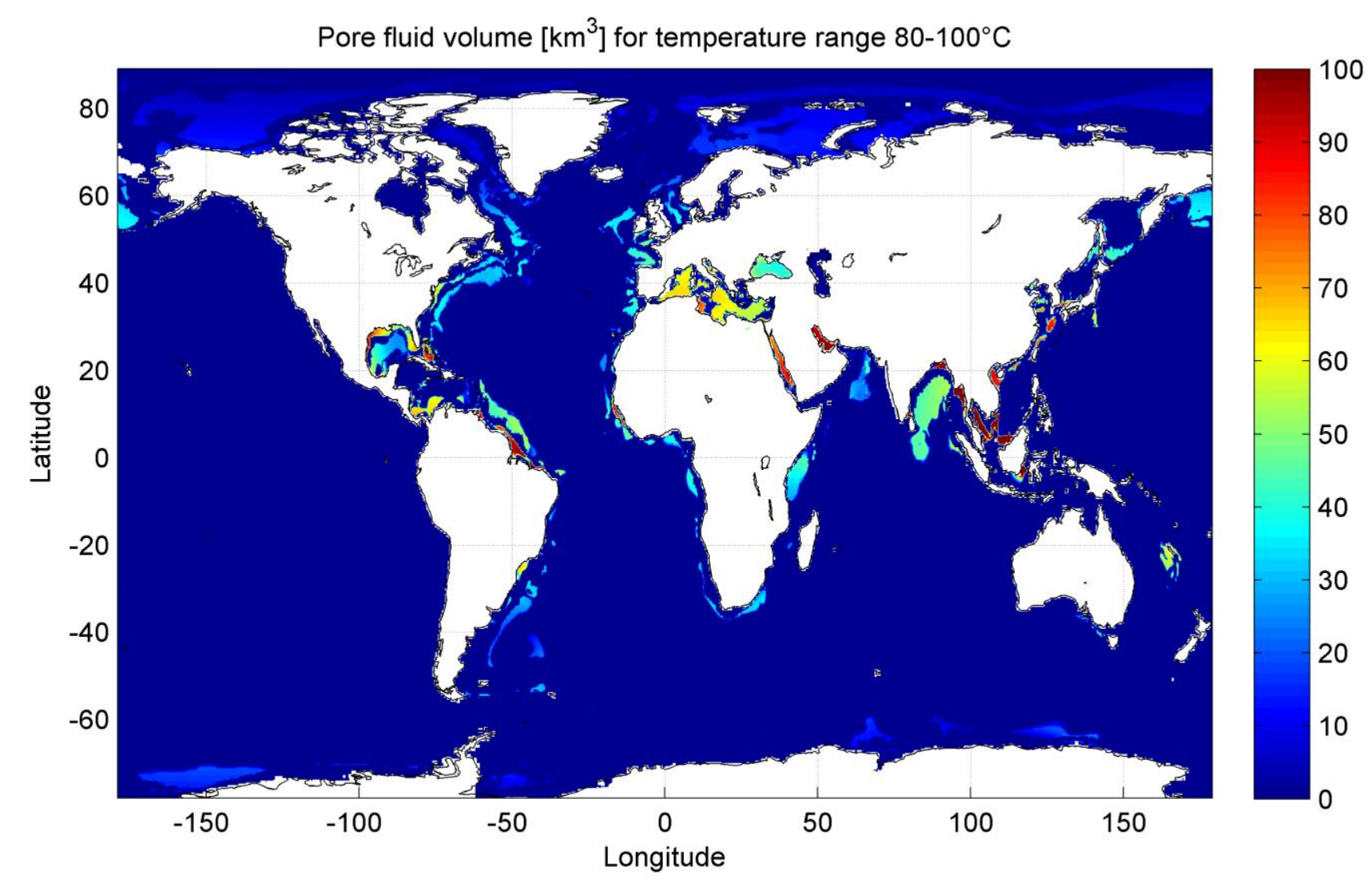




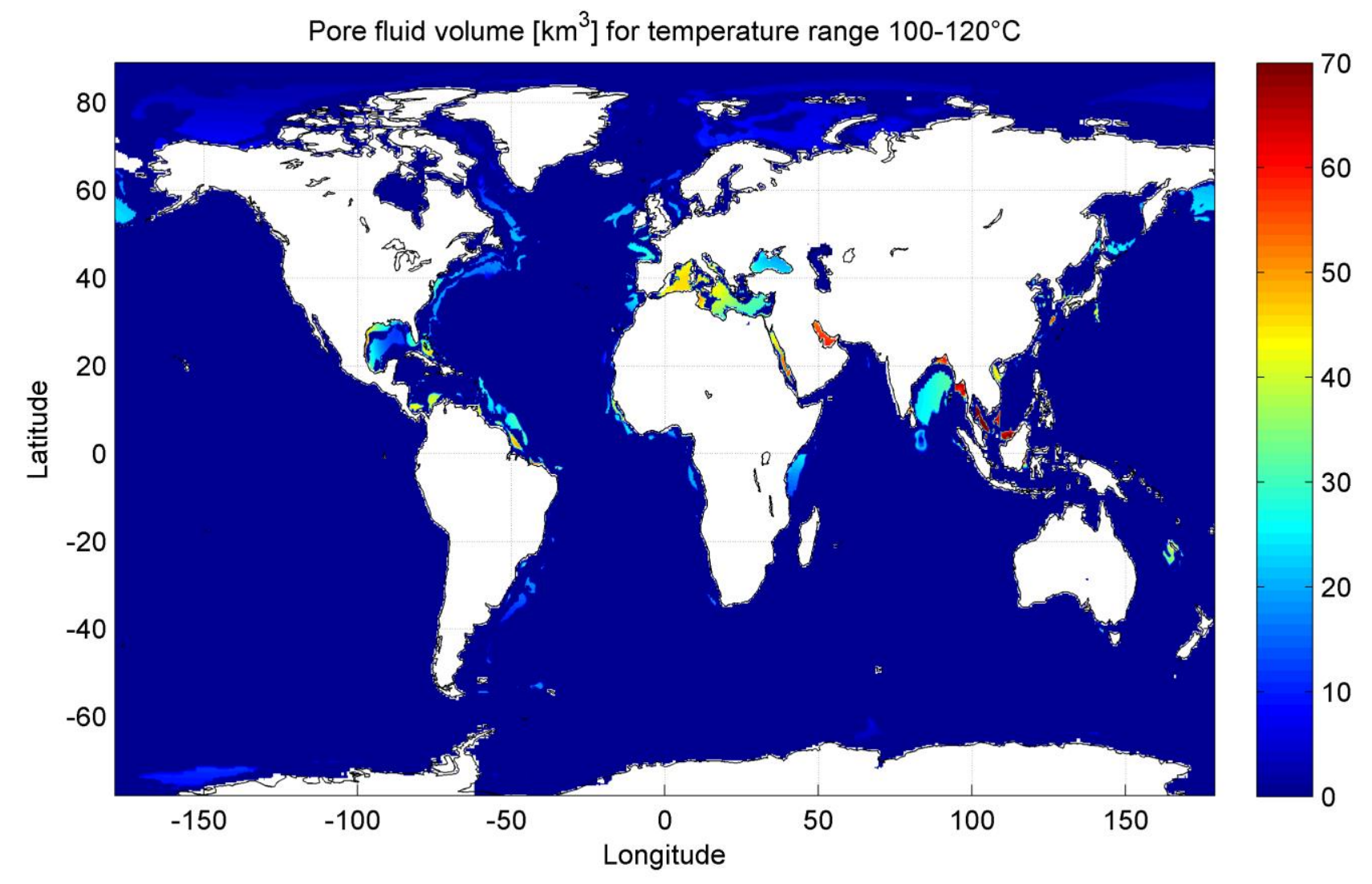




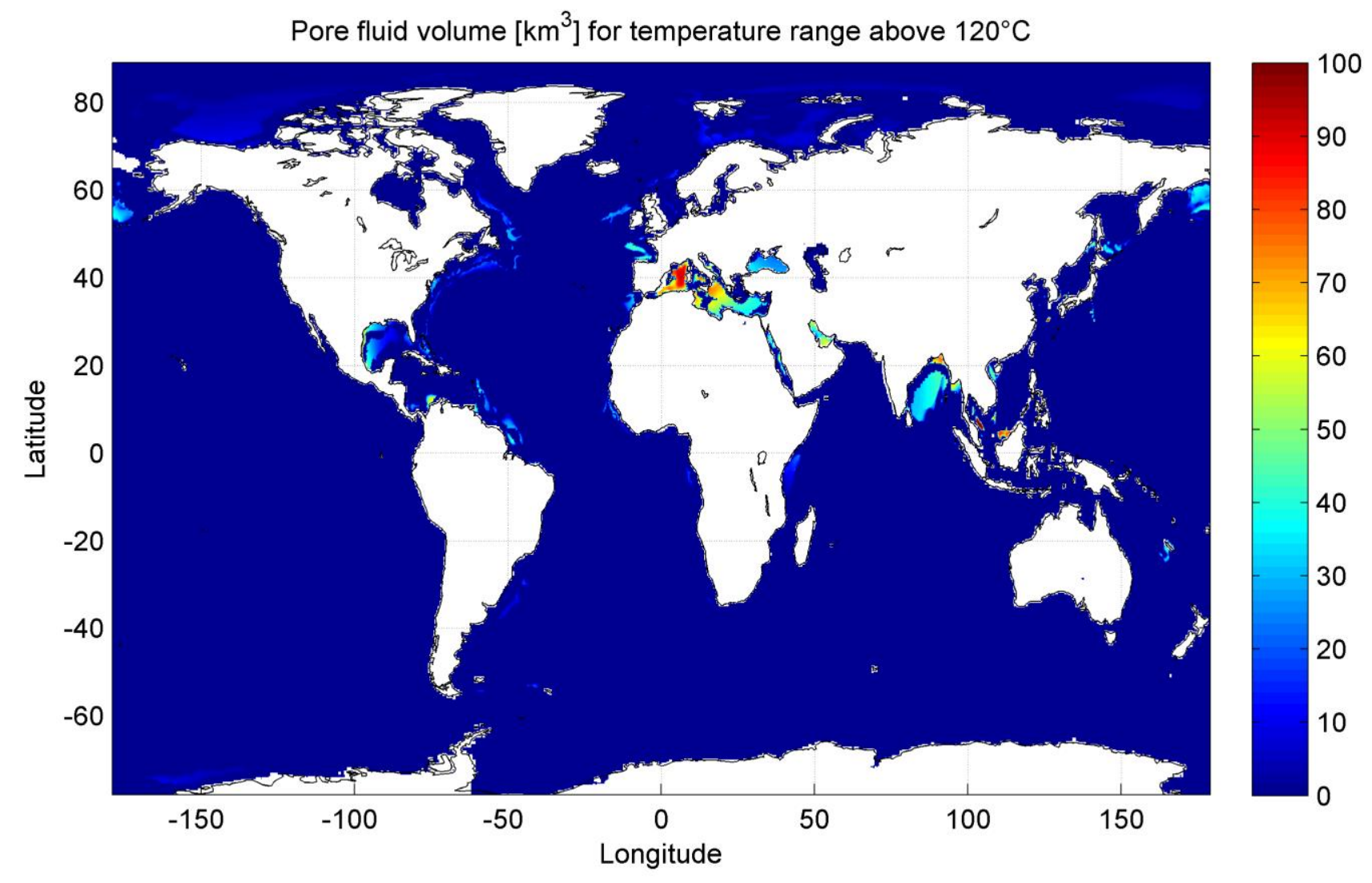

